\title{
Modelling Cost-Effectiveness of Biologic Treatments Based on Disease Activity Scores for the Management of Rheumatoid Arthritis in Spain
}

\author{
Ariel Beresniak, ${ }^{1,2}$ Rafael Ariza-Ariza, ${ }^{3}$ Jose Francisco Garcia-Llorente, ${ }^{4}$ \\ Antonio Ramirez-Arellano, ${ }^{5}$ and Danielle Dupont ${ }^{6}$ \\ ${ }^{1}$ R\&D, Data Mining International, 1215 Geneva, Switzerland \\ ${ }^{2}$ LIRAES, Paris Descartes University, 75270 Paris cedex 06, France \\ ${ }^{3}$ Rheumatology, Hospital Universitario Virgen Macarena, 41007 Sevilla, Spain \\ ${ }^{4}$ Rheumatology, Hospital de Basurto, 48013 Bilbao, Spain \\ ${ }^{5}$ Pharmacoeconomics Department, Bristol-Myers Squibb, Iberia, 28040 Madrid, Spain \\ ${ }^{6}$ Health Economics and Outcomes Strategy, Bristol-Myers Squibb Europe, 1420 Braine-l'Alleud, Belgium
}

Correspondence should be addressed to Ariel Beresniak, aberesniak@datamining-international.com

Received 14 February 2011; Accepted 2 May 2011

Academic Editor: B. L. Slomiany

Copyright (c) 2011 Ariel Beresniak et al. This is an open access article distributed under the Creative Commons Attribution License, which permits unrestricted use, distribution, and reproduction in any medium, provided the original work is properly cited.

\begin{abstract}
Background. The objective of this simulation model was to assess the cost-effectiveness of different biological treatment strategies based on levels of disease activity in Spain, in patients with moderate to severe active RA and an insufficient response to at least one anti-TNF agent. Methods. Clinically meaningful effectiveness criteria were defined using DAS28 scores: remission and Low Disease Activity State (LDAS) thresholds. Monte-Carlo simulations were conducted to assess cost-effectiveness over 2 years of four biological sequential strategies composed of anti-TNF agents (adalimumab, infliximab), abatacept or rituximab, in patients with moderate to severe active RA and an insufficient response to etanercept as first biological agent. Results. The sequential strategy including etanercept, abatacept and adalimumab appeared more efficacious over 2 years (102 days in LDAS) compared to the same sequence including rituximab as second biological option (82 days in LDAS). Cost-effectiveness ratios showed lower costs per day in LDAS with abatacept $(427 €)$ compared to rituximab as second biological option (508€). All comparisons were confirmed when using remission criteria. Conclusion. Model results suggest that in patients with an insufficient response to anti-TNF agents, the biological sequences including abatacept appear more efficacious and cost-effective than similar sequences including rituximab or cycled anti-TNF agents.
\end{abstract}

\section{Introduction}

Rheumatoid arthritis (RA) is a chronic, disabling disease with considerable impact on patients' lives, their families, and the society as a whole. RA prevalence rates are considered to be around $0.3-1.2 \%$, and epidemiological studies in Europe have shown intermediate prevalence rates, with slightly lower rates in Southern Europe [1-4]. The estimated prevalence in Spain is $0.5 \%$, with a women to men ratio in Spain estimated at $4: 1$ [5]. The incidence of RA increases with age [6]. Significant proportion of RA cases in the rural community remain undiagnosed despite patients' impaired functional status. In fact, diagnosed RA cases in the urban areas exceed those in the rural areas by 4 to 1 [5].

Multiple factors complicate the clinical assessment of RA, including the progressive nature of the disease and different genetic and environmental factors, as well as variable levels of individual patients' responsiveness to available treatment options. In addition, there is a lack of clinical head-tohead trials evaluating different treatment regimens. Given the substantial economic burden associated with RA both in terms of direct treatment costs and indirect costs to society, 
data about the efficacy and cost-effectiveness of RA treatment regimens is of particular interest to physicians, public policy makers, and health care agencies.

Optimal treatment has been shown to reduce RA symptoms, disease progression, and joint damage. Joint destruction is known to lead to severe physical impairment and to potential orthopaedic surgeries. In particular, clinical variables such as disease activity and the severity of symptoms are predictors of orthopedic surgery. Geographic and socioeconomic variables are also independently associated with the rate of orthopedic surgery [7]. Hence, depending on the severity of the disease, different RA treatment strategies may lead to different outcomes and use of healthcare resources.

Nonsteroidal anti-inflammatory drugs, corticosteroids, or traditional disease-modifying antirheumatic drugs (DMARDs) are usually the first line of RA therapy. In Spain, RA patients typically show a moderate degree of disease activity despite the use of DMARDs. The proportion of extraarticular manifestations in Spanish patients with RA is similar to that found in other Mediterranean populations and lower than that reported in Northern Europe or North America [8].

When DMARDs are no longer efficacious due to disease progression, or when patients experience serious side effects or have high inflammatory markers indicating an aggressive disease onset, biological agents may be considered. These options include antitumor necrosis factor (anti-TNF) agents such as etanercept (ETA), adalimumab (ADA), and infliximab (INF). The introduction of anti-TNF agents has set new standards in RA treatment. These agents not only reduce the signs and symptoms of the disease but they also reduce the radiographic progression. However, patients who are likely candidates for anti-TNF therapies usually have complicated clinical profiles. Unless they are treated for early RA to prevent disease progression, they also often present advanced stages of the disease [9].

In clinical trials, anti-TNF agents have been efficacious, particularly in patients whose disease had failed to show improvement with prior DMARDs. However, as much as these targeted therapies have advanced the field of RA treatment, they also have limited efficacy. Only a small proportion of patients achieve $70 \%$ improvement according to the American College of Rheumatology (ACR 70) clinical response criteria, and remissions are exceedingly rare. Moreover, the percentage of patients who do not achieve even the lowest response (namely, an ACR20 response) amounts to 28$58 \%$ [9]. For patients who do not respond to anti-TNF therapy, new biological agents are now available in Spain, each showing a distinct and different mechanism of action from anti-TNF agents. They include abatacept (ABA) and rituximab (RTX).

Currently, Spanish patients with moderate to severe RA and an insufficient response (IR) to anti-TNF therapy can be treated with either ABA or RTX or be switched to another anti-TNF agent [10]. However, there are no randomized controlled studies which have assessed the efficacy of successive anti-TNF agents in patients with an IR to the previous agent. And while one Spanish observational multicentre study showed that RA treatment with ETA compared to INF and ADA reduced hospital costs [11], there are no study in Spain which assessed the impact on health care resources and associated costs of using up to three biological agents. Comparative studies are scarce due to several factors: biological agents are still relatively new and the treatment of moderate to severe RA often requires multiple treatment strategies used sequentially. Moreover, such complex treatment strategies are almost impossible to reproduce in clinical trial settings.

Given the lack of head-to-head clinical trials, decision analytic models are useful to assess and compare expected effectiveness and costs of sequential RA biological strategies based on RA treatment cost estimates. A model is a mathematic formula linking different variables to generate results relevant to a given environment, such as local medical practices. Results generated by modelling approaches thus provide unique information on the expected effectiveness, overall costs, and cost effectiveness of different treatment strategies to assist clinical decision making as well as resource allocations decisions from public health officials.

This paper proposes an advanced modelling approach to evaluate the effectiveness, the costs and cost effectiveness of different sequential biological treatment regimens for managing moderate to severe RA in Spain, in patients with an IR to at least one anti-TNF agent. Using the perspective of the Spanish health care system, the model considers a target population of RA patients with an IR to anti-TNF therapy, clinically relevant effectiveness criteria based on levels of disease activity, local treatment patterns informed by Spanish experts' opinions, and estimated treatment costs associated with different treatment sequences. Similar approaches were published by Russell et al. [12] in Canada and Saraux et al. [13] in France.

\section{Materials and Methods}

The objective of this model was to simulate the costeffectiveness of sequential biological strategies according to medical practices in Spain in patients with moderate to severe RA and an IR to at least one anti-TNF agent. In the absence of studies assessing RA treatment costs by level of disease activity in Spain, RA direct medical costs were derived from a standard cost analysis performed with a panel of three expert rheumatologists from different Spanish districts. As suggested by similar approaches $[12,13]$, three categories of disease activity were defined according to DAS28 (disease activity score 28 ) thresholds: remission (RS: DAS28< 2.6), low disease activity state (LDAS: DAS28 $\leq 3.2$ ), and moderate to high disease activity state (MHDAS: DAS28 > 3.2).

Resource utilization was estimated per 6-month intervals considering medical resource utilization items related to RA clinical management in Spain: rheumatologists and other specialist visits, general practitioner visits, laboratory tests, hospitalization, imaging, physiotherapy, surgery, medical transportation, and nursing. (Table 1) Unit costs from the national healthcare provider perspective were collected and simulated using distribution ranges for each item. A cost model was developed to compute the specific distribution of each resource item in order to calculate total medical 
TABLE 1: Estimated medical resource utilization over 6 months per level of disease activity, excluding biological drug costs (in Euros).

\begin{tabular}{|c|c|c|c|c|c|c|c|c|c|}
\hline & \multicolumn{3}{|c|}{ RS $($ DAS $28<2.6)$} & \multicolumn{3}{|c|}{ LDAS $($ DAS28 $\leq 3.2)$} & \multicolumn{3}{|c|}{ MHDAS (DAS28 > 3.2) } \\
\hline & Min & Mean & Max & Min & Mean & Max & Min & Mean & Max \\
\hline $\begin{array}{l}\text { Rheumatologist } \\
\text { visits }\end{array}$ & 40.8 & - & 290 & & 81.67 & & 122.5 & & 870 \\
\hline Orthopedist visits & - & - & - & - & - & - & - & 40.8 & - \\
\hline $\begin{array}{l}\text { Rehabilitation } \\
\text { specialist visits }\end{array}$ & - & - & - & - & - & - & - & 40.8 & - \\
\hline $\begin{array}{l}\text { Other specialist } \\
\text { visits }\end{array}$ & - & - & - & - & - & - & - & 10.2 & - \\
\hline GP visits & - & - & - & - & 28.2 & - & 28.2 & - & 250 \\
\hline $\begin{array}{l}\text { Lab (standard } \\
\text { package) }\end{array}$ & 32.5 & - & 229.2 & - & 229.2 & - & 343.8 & - & 195.4 \\
\hline X-Ray Hands/Feet & - & - & - & - & - & - & 4 & - & 18 \\
\hline MRI & - & - & - & - & - & - & - & 290.2 & - \\
\hline Hospital & - & - & - & - & - & - & - & 1754.5 & - \\
\hline Physio (\#days) & - & - & - & - & - & - & 449.7 & - & 3979 \\
\hline Surgery Knee & - & - & - & - & - & - & - & 590.4 & - \\
\hline Surgery Hands & - & - & - & - & - & - & - & 94.62 & - \\
\hline Surgery Feet & - & - & - & - & - & - & - & 109.8 & - \\
\hline $\begin{array}{l}\text { Medical } \\
\text { transportation* }\end{array}$ & - & - & - & - & - & - & 212.4 & - & 529.6 \\
\hline Nursing & - & - & - & 0 & - & 23.6 & 10 & - & 70.9 \\
\hline
\end{tabular}

RS: remission state.

LDAS: low disease activity state.

MHDAS: moderate to high disease activity state.

DAS: disease activity score.

*Transportation to hospital or clinic.

direct costs for each of the three disease activity categories. Biological drug costs and infusion costs were calculated and integrated separately in the model based on recommended dosing in Spain (Table 2).

Because the DAS28 score is an ordinal scale (not "cardinal" with equal grades), it was not possible to calculate cost-effectiveness ratios expressed in cost per unit of DAS28 score. Consequently, two dichotomous clinical endpoints were selected to reflect RA treatment targets, that is, to achieve LDAS or remission, or not (success/no success). Effectiveness estimates of biological therapies in anti-TNF inadequate responders are presented in Tables 3 and 4 and were derived from published clinical trials available at the time of model development, namely, the ATTAIN trial and long-term extension study for abatacept $[14,15]$, the ReAct open label trial for anti-TNF agents [16] and for rituximab, the REFLEX trial and open-label extension analysis in antiTNF inadequate responders $[17,18]$. Given that retreatment intervals for rituximab are not well established, the model assumed a retreatment at 6 months for a sustained DAS28 response over time. Conservatively, the effectiveness of antiTNF maintenance therapy at 24 months was modelled as being similar to using abatacept (ATTAIN trial). Hence, the percentage of patients achieving LDAS and RS at each simulated 6-month time points was used to populate the model over a 2-year time horizon. The overall effectiveness was expressed in expected number of days in LDAS and in RS for each treatment sequence.

Four simulation models were developed representing the 4 sequences of 3 biological agents over a two-year time horizon, namely, Sequence A: ETA-ABA-ADA, Sequence B: ETA-RTX-ADA, Sequence C: ETA-ADA-ABA, and Sequence D: ETA-ADA-INF.

Sequence A (Figure 1) thus simulates a cohort of RA patients with an IR to one anti-TNF agent (ETA) over the first 6 months. All IR patients are then switched to ABA and then to ADA in case of an IR to ABA. Likewise, Sequence $B$ simulates the same patient population with an IR to one anti-TNF agent (ETA) over the first 6 months, after which all patients were switched to RTX and then to ADA in case of an IR to RTX. Sequence C simulates a cohort of RA patients with an IR to two anti-TNF agents (i.e., ETA during the first 6 months followed by ADA during the next 6 months). Then, all patients were switched to ABA. Sequence D simulates the same patient cohort of patients with an IR to two anti-TNF agents (ETA and ADA), then all patients were switched to a third anti-TNF agent (INF).

Since current medical practices and different treatment sequences are not explicitly documented in RA, simulation models represent the best approach for comparing these four strategies by taking into account costs and available clinical evidence. Monte Carlo simulations (using 5000 iterations of 
TABLE 2: Estimated biological treatment costs.

\begin{tabular}{|c|c|c|c|c|}
\hline \multirow{2}{*}{$\begin{array}{l}\text { Biological therapies } \\
\text { Abatacept (250 mg vial) }\end{array}$} & \multicolumn{2}{|c|}{ Year 1} & \multicolumn{2}{|c|}{ Year 2} \\
\hline & 1st 6 months & 2nd 6 months & 1st 6 months & 2nd 6 months \\
\hline Estimated number of vials per year & 37.8 & & 35.1 & \\
\hline Infusion cost/IV infusion & $56.69 €$ & & $56.69 €$ & \\
\hline Estimated reimbursement cost per year & $13,449.86 €$ & & $12,489.15 €$ & \\
\hline Estimated cost per six months ( 26 weeks) & $6,724.93 €$ & $6,724.93 €$ & $5,764.22 €$ & $6,724.93 €$ \\
\hline Adalimumab (40 mg syringe) & 1st 6 months & 2nd 6 months & 1st 6 months & 2nd 6 months \\
\hline Estimated number of prefilled syringes per year & 26 & & 26 & \\
\hline Estimated reimbursement cost per year & $13,367.77 €$ & & $13,367.77 €$ & \\
\hline Estimated cost per six months ( 26 weeks) & $6,683.89 €$ & $6,683.89 €$ & $6,683.89 €$ & $6,683.89 €$ \\
\hline Etanercept (25 mg vial) & 1st 6 months & 2nd 6 months & 1st 6 months & 2nd 6 months \\
\hline Estimated number of vials per year & 104 & & 104 & \\
\hline Estimated reimbursement cost per year & $12,313.86 €$ & & $12,313.86 €$ & \\
\hline Estimated cost per six months ( 26 weeks) & $6,156.93 €$ & $6,156.93 €$ & $6,156.93 €$ & $6,156.93 €$ \\
\hline Infliximab (100 mg vial) & 1st 6 months & 2nd 6 months & 1st 6 months & 2nd 6 months \\
\hline Estimated number of vials per year & 11.5 & 8.1 & 8.8 & 8.8 \\
\hline Infusion cost/IV infusion & $56.69 €$ & & $56.69 €$ & \\
\hline Estimated reimbursement cost per year & $10,966.75 €$ & & $9,794.14 €$ & \\
\hline Estimated cost per six months ( 26 weeks) & $6,446.38 €$ & $4,520.37 €$ & $4,897.07 €$ & $4,897.07 €$ \\
\hline Rituximab (500 mg vial) & 1st 6 months & 2nd 6 months & 1st 6 months & 2nd 6 months \\
\hline Estimated number of vials per year & 8.00 & & 8.00 & \\
\hline Infusion cost/IV infusion & $56.69 €$ & & $56.69 €$ & \\
\hline Estimated reimbursement cost per year & $10,202.76 €$ & & $10,202.76 €$ & \\
\hline Estimated cost per six months ( 26 weeks) & $5,101.38 €$ & $5,101.38 €$ & $5,101.38 €$ & $5,101.38 €$ \\
\hline
\end{tabular}

TABLE 3: Summary of effectiveness probabilities (percentage of patients achieving LDAS).

\begin{tabular}{|c|c|c|c|}
\hline Biological agent & & $\%$ LDAS & Source \\
\hline Abatacept after IR to anti-TNF therapy & $\begin{array}{l}\text { Induction-Month } 12 \\
\text { Maintenance } \\
\text { Month } 18 \\
\text { Month } 24\end{array}$ & $\begin{array}{c}18.3 \% \\
24.2 \% \\
28 \%\end{array}$ & $\begin{array}{l}\text { ATTAIN + LTE study (Genovese 2007) } \\
\text { ATTAIN + LTE study (Genovese 2007) } \\
\text { ATTAIN + LTE study (Genovese 2007) }\end{array}$ \\
\hline Abatacept after IR to 2 anti-TNF agents & $\begin{array}{l}\text { Induction-Month } 18 \\
\text { Maintenance-Month } 24\end{array}$ & $\begin{array}{l}24.5 \% \\
21.5 \%\end{array}$ & $\begin{array}{l}\text { ATTAIN reanalysis after IR to } 2 \text { anti-TNF } \\
\text { agents (EULAR 2008) } \\
\text { ATTAIN reanalysis after IR to } 2 \text { anti-TNF } \\
\text { agents }\end{array}$ \\
\hline Anti-TNF agents & $\begin{array}{l}\text { Induction-Month } 18 \\
\text { Maintenance-Month } 24\end{array}$ & $\begin{array}{c}11 \% \\
21.5 \%\end{array}$ & $\begin{array}{c}\text { REACT trial (Bombardieri 2007) } \\
\text { ATTAIN reanalysis after IR to } 2 \text { anti-TNF } \\
\text { agents }\end{array}$ \\
\hline Rituximab after IR to anti-TNF therapy & $\begin{array}{l}\text { Induction-Month } 12 \\
\text { Maintenance } \\
\text { Month } 18 \\
\text { Month } 24\end{array}$ & $\begin{array}{l}13 \% \\
25 \% \\
29 \%\end{array}$ & $\begin{array}{c}\text { REFLEX + LTE study (Keystone 2007) } \\
\text { REFLEX + LTE study (Keystone 2007) } \\
\text { Keystone (EULAR 2007) }\end{array}$ \\
\hline DMARDS & Month 24 & $5 \%$ & Clinical experts opinion \\
\hline
\end{tabular}

IR: insufficient response; LDAS: low disease activity State (DAS28 $\leq 3.2)$. 
TABLE 4: Summary of effectiveness probabilities (percentage of patients achieving RS).

\begin{tabular}{|c|c|c|c|}
\hline Biological agent & & $\% \mathrm{RS}$ & Source \\
\hline $\begin{array}{l}\text { Abatacept after IR to } \\
\text { anti-TNF therapy }\end{array}$ & $\begin{array}{l}\text { Induction-Month } 12 \\
\text { Maintenance } \\
\text { Month } 18 \\
\text { Month } 24\end{array}$ & $\begin{array}{l}11.1 \% \\
13.9 \% \\
17.1 \%\end{array}$ & $\begin{array}{l}\text { ATTAIN + LTE study (Genovese 2007) } \\
\text { ATTAIN + LTE study (Genovese 2007) } \\
\text { ATTAIN + LTE study (Genovese 2007) }\end{array}$ \\
\hline $\begin{array}{l}\text { Abatacept after IR to } 2 \\
\text { anti-TNF agents }\end{array}$ & $\begin{array}{l}\text { Induction-Month } 18 \\
\text { Maintenance-Month } 24\end{array}$ & $\begin{array}{l}8.45 \% \\
14.4 \%\end{array}$ & $\begin{array}{l}\text { ATTAIN reanalysis after IR to } 2 \\
\text { anti-TNF agents } \\
\text { ATTAIN reanalysis after IR to } 2 \\
\text { anti-TNF agents }\end{array}$ \\
\hline Anti-TNF agents & $\begin{array}{l}\text { Induction-Month } 18 \\
\text { Maintenance-Month } 24\end{array}$ & $\begin{array}{c}4 \% \\
14.4 \%\end{array}$ & $\begin{array}{c}\text { REACT trial (Bombardieri 2007) } \\
\text { ATTAIN reanalysis after IR to } 2 \\
\text { anti-TNF agents }\end{array}$ \\
\hline $\begin{array}{l}\text { Rituximab after IR to } \\
\text { anti-TNF therapy }\end{array}$ & $\begin{array}{l}\text { Induction-Month } 12 \\
\text { Maintenance } \\
\text { Month } 18 \\
\text { Month } 24\end{array}$ & $\begin{array}{c}6 \% \\
13 \% \\
12 \%\end{array}$ & $\begin{array}{c}\text { REFLEX + LTE study (Keystone 2007) } \\
\text { REFLEX + LTE study (Keystone 2007) } \\
\text { Keystone (EULAR 2007) }\end{array}$ \\
\hline DMARDS & Month 24 & $1 \%$ & Clinical experts opinion \\
\hline
\end{tabular}

IR: insufficient response; RS: remission (DAS28 < 2.6).

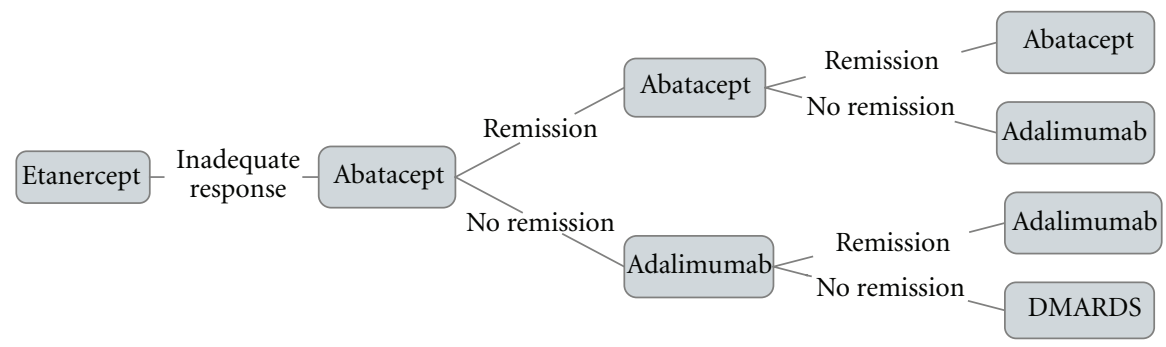

FIGURE 1: Model structure of Sequence A using "remission" as clinical outcome.

random numbers) were computed for each sequence. This approach is known as a probabilistic sensitivity analysis. This technique is recommended as best practice in economic modelling to assess the potential impact of parameters distribution on the results. Each model generated mean values and standard deviations of costs, effectiveness, and mean costeffectiveness ratios (MCER) over 2 years. Incremental costeffectiveness ratios (ICER) have been calculated for Sequence A versus Sequence B. Statistical tests (mean comparison tests) were performed to calculate potential significant differences.

\section{Results and Discussion}

3.1. Resource Utilization for RA Medical Management Over 6 Months. Direct medical costs (excluding biological therapies costs) were calculated according to three disease activity DAS28 categories: RS, LDAS, and MHDAS. Direct medical treatment costs over 6 months were estimated at $295 €(S D=$ 92) for patient in $\mathrm{RS}, 350 €(\mathrm{SD}=7)$ for patient in LDAS and $6,135 €(\mathrm{SD}=1279)$ for patient in MHDAS (Figures 2(a), 2(b), and 2(c)). Hence, achieving LDAS or remission was associated with lower medical costs. Higher direct medical costs for patients in moderate to high disease activity reflect the higher use of health care services. Key costs drivers were mainly due to physiotherapy and hospitalization (Table 1).

3.2. Effectiveness and Cost-Effectiveness over 2 Years. Effectiveness and cost-effectiveness results over 2 years are summarized in Table 5.

3.3. Achieving Remission. Sequence A, which represented the use of abatacept after an IR to one anti-TNF agent (ETA), appeared significantly $(P<0.01)$ more efficacious over 2 years (52 days in RS) when compared to a similar Sequence $\mathrm{B}$ which included rituximab (33 days in RS). Corresponding mean cost-effectiveness ratios showed significantly lower costs $(P<0.01)$ per day in remission for Sequence $\mathrm{A}$ which included abatacept after an IR to one anti-TNF agent $(846 €)$, as compared to Sequence B which included rituximab $(1301 €)$. Should the incremental cost-effectiveness ratio (ICER) be considered to compare Sequence A versus Sequence B, then the ICER would be estimated at $84 €$ per additional day in remission. The ICER is another way to present the results and is calculated by dividing the difference in overall treatment costs between Sequence A and Sequence $B$, by the difference in overall effectiveness between Sequence $A$ and Sequence B (expected number of days in remission). 


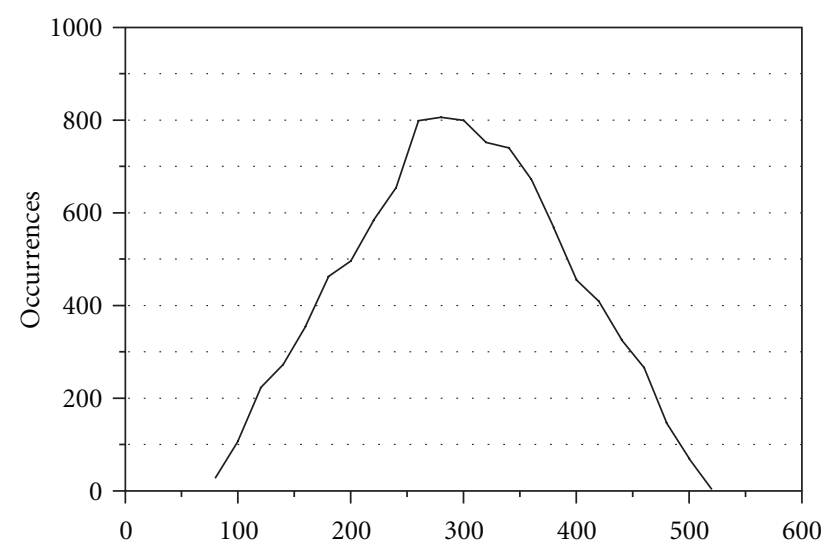

(a) 6-month medical treatment costs for patients in remission (excluding biological drug costs)

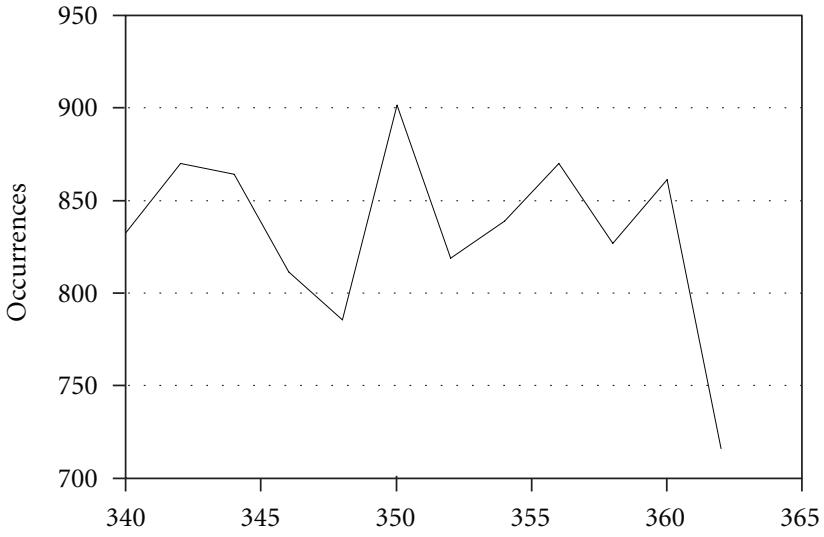

(b) 6-month medical treatment costs for patients in LDAS (excluding biological drug costs)

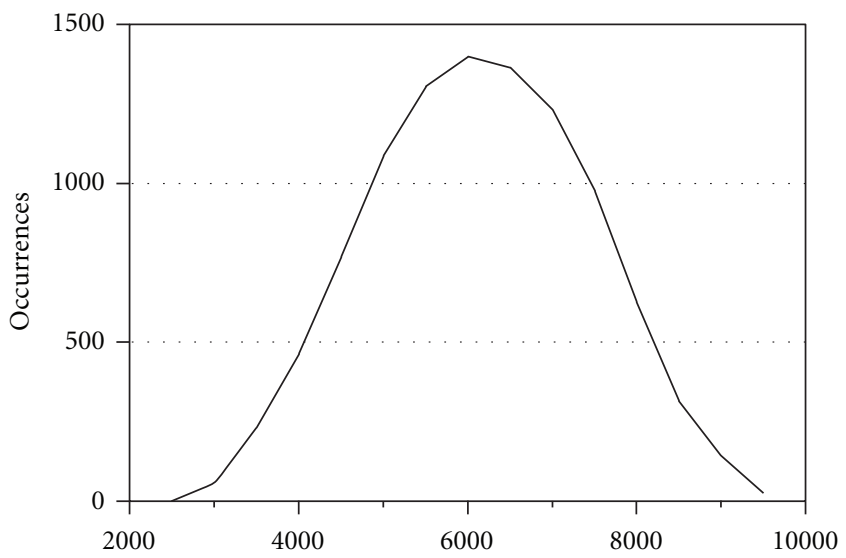

(c) 6-month medical treatment costs for patients in moderate to high disease activity state (excluding biological drug costs)

FIGURE 2: 6-month medical treatment costs for patients in remission (a), low disease activity state (b), and moderate to high disease activity (c), excluding biological drug costs (in Euros).

TABle 5: Effectiveness and mean cost-effectiveness (MCER) for Sequences a, b, c, d over 2 years.

\begin{tabular}{lcccc}
\hline & $\begin{array}{c}\text { Expected number of } \\
\text { days in RS }\end{array}$ & $\begin{array}{c}\text { Expected number of } \\
\text { days in LDAS }\end{array}$ & $\begin{array}{c}\text { MCER (estimated } \\
\text { mean cost per day in } \\
\text { RS) }\end{array}$ & $\begin{array}{c}\text { MCER (estimated } \\
\text { mean cost per day in } \\
\text { LDAS) }\end{array}$ \\
\hline Sequence A: ETA-ABA-ADA & 52 & 102 & $846 €$ & $427 €$ \\
Sequence B: ETA-RTX-ADA & 33 & 82 & $1,301 €$ & $508 €$ \\
Sequence C: ETA-ADA-ABA & 22 & 64 & $2,489 €$ & $729 €$ \\
Sequence D: ETA-ADA-INF & 10 & 32 & $4,568 €$ & $1,352 €$ \\
\hline
\end{tabular}

RS: remission.

LDAS: low disease activity state.

MCER: mean cost-effectiveness ratio.

However, contrary to the mean cost-effectiveness ratio, the ICER does not allow to compare the different sequences to determine which one appears to be the most cost-effective.

Sequence $\mathrm{C}$ which represented the use of abatacept after an IR to two anti-TNF agents (ETA and ADA) appeared significantly $(P<0.01)$ more efficacious over 2 years $(22$ days in RS) compared to a similar Sequence D which included a third anti-TNF agent (INF) (10 days in RS). Corresponding mean cost-effectiveness ratios showed significantly lower costs $(P<0.01)$ per day in remission for Sequence $\mathrm{C}$ which included abatacept after two anti-TNF agents $(2489 €)$ compared to Sequence D which used three successive antiTNF agents $(4568 €)$.

3.4. Achieving LDAS. Sequence A representing the use of abatacept after an IR to one anti-TNF agent (ETA) appeared significantly $(P<0.01)$ more efficacious over 2 years $(102$ days in LDAS) compared to a similar Sequence B which 
included rituximab (82 days in LDAS). Corresponding mean cost-effectiveness ratios showed significantly lower costs $(P<$ 0.01) per day in LDAS for Sequence A which included abatacept after an IR to a first anti-TNF agent (427€) compared to a similar Sequence $\mathrm{B}$ including rituximab $(508 €)$. The ICER between Sequence A versus Sequence B is estimated at $91 €$ per additional day in LDAS.

Sequence $\mathrm{C}$ representing the use of abatacept after an IR to two successive anti-TNF agents (ETA and ADA) appeared significantly $(P<0.01)$ more efficacious over 2 years $(64$ days in LDAS) compared to Sequence D, which included a third anti-TNF (INF) (32 days in LDAS). Corresponding mean cost-effectiveness ratios showed significantly lower costs $(P<$ 0.01) per day in LDAS in Sequence C, including abatacept after two anti-TNF agents (729€), as compared to Sequence $\mathrm{D}$ using three successive anti-TNF agents (1352€).

\section{Discussion}

RA is a complex disease whose clinical progression is highly dependent on environmental and genetic factors, as well as on the sequence of different treatment options. Moreover, questions remain regarding the optimal sequencing of biological agents due to a lack of head-to-head randomized control trials to compare different sequential strategies. The implementation of such complex and costly experimental multiarms longitudinal studies also prove to be impractical.

This explains why the field of RA management has recently seen a proliferation of modelling approaches to assess the cost-effectiveness of different treatment strategies [12, 19-21]. In particular, simulation modelling allows to examine the potential benefits of different treatment strategies used sequentially to assist decisions regarding those that are shown to be effective and cost-effective. As robust models typically use validated assumptions and published clinical evidence, modelling is also convenient to evaluate long-term consequences in terms of effectiveness and costs $[22,23]$.

Because so much of the model's conclusions rest on the effectiveness criteria, special attention should be paid to the selection of objective and relevant clinical outcomes. Two aspects of the present model warrant special discussion, namely, the treatment intervals and the outcome measures. The model allows a decision to switch biological therapy at each 6-month time point in case of an IR to the previous biological agent. This is because most clinical trials report clinical efficacy every 6 months and because a decision to switch biological therapy at 6 months in case of an insufficient response also reflects common medical practice. As for rituximab, retreatment intervals are not well defined and RA symptoms have been reported to reappear between treatment courses, which may lead to a fluctuating DAS28 response over time. As this simulation model is based on achieving and maintaining a LDAS or remission at each 6month time point, rituximab retreatment intervals were set as 6 months in responders. This corresponds to the rituximab US product monograph indicating that most of the RA patients who received additional courses in clinical trials did so 24 weeks after the previous course and none were retreated sooner than 16 weeks.

Since the ultimate RA treatment objective is to achieve LDAS or remission and to maintain such response over time, we chose these levels of disease activity as the most meaningful effectiveness endpoints for this cost-effectiveness analysis. However, such as the HAQ score, the DAS28 score is based on an ordinal scale. It would then be methodologically incorrect to calculate cost-effectiveness ratios expressed as cost per unit of DAS28 or cost per unit of HAQ, even though such approaches using the HAQ have been published [21]. In order to avoid this limitation of scale metric properties, we chose to use a "success/no success" dichotomous criteria based on achieving remission or LDAS according to welldefined DAS28 therapeutic success thresholds. Not only is this approach methodologically robust when dealing with an ordinal scale, but it is also more clinically meaningful to physicians, as compared to cost-utility models which express results in QALYs (quality-adjusted life years gained). As costutility assessments are also presented as "cost-effectiveness" analyses, they use the QALY as subjective effectiveness measure [24-27]. While of theoretical interest, there is however an active scientific debate regarding the objective validity and reliability of the cost-utility (QALY) method [24, 28, 29]. The key concern is that varying some of the assumptions used to derive the QALY may lead to widely divergent and inconsistent results $[24,29,30]$. This is also explained by the fact that different utility instruments (such as, the HUI, EQ5D (EuroQol), and SF-6D questionnaires) may lead to utility scores which are statistically significantly different in RA patients [31, 32]. Given the variety of existing utility measurements, interpretation of cost-utility results expressed in cost per QALYs should be done with considerable caution. We believe that more objective criteria-such as evidencebased clinical outcomes-represent a more reliable measure for assessing innovative RA treatments. Since the DAS28 response has a prognostic value for joint damage over time [33], we chose it as a relevant outcome criterion. However, the improvement in quality of life also being of paramount importance when treating RA, this clinical improvement must be considered as a specific clinical outcome.

\section{Conclusion}

These results derived from simulation models offer useful additional information to assist decision making. While they are not meant to supplant treatment guidelines nor to replace further clinical evidence, simulation models nonetheless represent a promising approach to compare complex treatment strategies in chronic diseases such as RA.

Considering the Spanish healthcare perspective and levels of disease activity, this analysis shows that a biological sequence strategy using abatacept after an insufficient response to one anti-TNF agent appears to be more effective and cost-effective versus a similar sequence using rituximab and that a biological sequence using abatacept after an insufficient response to 2 anti-TNF agents appears to be more effective and cost-effective than a similar sequence using anti-TNF agents only. 


\section{References}

[1] S. Brighton, A. de la Harpe, D. van Staden, J. Badenhorst, and O. Myers, "The prevalence of rheumatoid arthritis in a rural African population," Journal of Rheumatology, vol. 15, no. 3, pp. 405-408, 1988.

[2] M. Cimmino, M. Parisi, G. Moggiana, G. Mela, and S. Accardo, "Prevalence of rheumatoid arthritis in Italy: the Chiavari study," Annals of the Rheumatic Diseases, vol. 57, no. 5, pp. 315-318, 1998.

[3] M. Simonsson, S. Bergman, L. T. H. Jacobsson, I. F. Petersson, and B. Svensson, "The prevalence of rheumatoid arthritis in Sweden," Scandinavian Journal of Rheumatology, vol. 28, no. 6, pp. 340-343, 1999.

[4] F. Guillemin, S. Durieux, J. P. Daures et al., "Costs of rheumatoid arthritis in France: a multicenter study of 1109 patients managed by hospital-based rheumatologists," Journal of Rheumatology, vol. 31, no. 7, pp. 1297-1304, 2004.

[5] L. Carmona, V. Villaverde, C. Hernández-García, J. Ballina, R. Gabriel, and A. Laffon, "The prevalence of rheumatoid arthritis in the general population of Spain," Rheumatology, vol. 41, no. 1, pp. 88-95, 2002.

[6] J. Carbonell, T. Cobo, A. Balsa, M. Descalzo, L. Carmona, and SERAP Study Group, "The incidence of rheumatoid arthritis in Spain: results from a nationwide primary care registry," Rheumatology, vol. 47, no. 7, pp. 1088-1092, 2008.

[7] E. Loza, L. Abasolo, D. Clemente et al., "Variability in the use of orthopedic surgery in patients with rheumatoid arthritis in Spain," Journal of Rheumatology, vol. 34, no. 7, pp. 1485-1490, 2007.

[8] L. Carmona, I. González-Alvaro, A. Balsa, M. A. Belmonte, X. Tena, and R. Sanmartí, "Rheumatoid arthritis in Spain: occurrence of extra-articular manifestations and estimates of disease severity," Annals of the Rheumatic Diseases, vol. 62, no. 9, pp. 897-900, 2003.

[9] K. Redlich, G. Schett, G. Steiner, S. Hayer, E. Wagner, and J. Smolen, "Rheumatoid arthritis therapy after tumor necrosis factor and interleukin-1 blockade," Arthritis and Rheumatism, vol. 48, no. 12, pp. 3308-3319, 2003.

[10] K. Hyrich, M. Lunt, K. Watson, D. Symmons, A. Silman, and British Society for Rheumatology Biologics Register, "Outcomes after switching from one anti-tumor necrosis factor alpha agent to a second anti-tumor necrosis factor alpha agent in patients with rheumatoid arthritis: results from a large UK national cohort study," Arthritis and Rheumatism, vol. 56, no. 1, pp. 13-20, 2007.

[11] C. Rubio-Terres, J. P. Ordovás Baines, R. Pla Poblador et al., "Use and cost of biological disease -modifying anti-rheumatic drugs in Spain (PRAXIS study)," Farmacia Hospitalaria, vol. 31, no. 2, pp. 78-92, 2007.

[12] A. Russell, A. Beresniak, L. Bessette et al., "Cost-effectiveness modeling of abatacept versus other biologic agents in DMARDS and anti-TNF inadequate responders for the management of moderate to severe rheumatoid arthritis," Clinical Rheumatology, vol. 28, no. 4, pp. 403-412, 2008.

[13] A. Saraux, L. Gossec, P. Goupille et al., "Cost-effectiveness modelling of biological treatment sequences in moderate to severe rheumatoid arthritis in France," Rheumatology, vol. 49, pp. 733-740, 2010.

[14] M. C. Genovese, J. C. Becker, M. Schiff et al., "Abatacept for rheumatoid arthritis refractory to tumor necrosis factor $\alpha$ inhibition," New England Journal of Medicine, vol. 353, no. 11, pp. 1114-1123, 2005.
[15] M. C. Genovese, M. Schiff, M. Luggen et al., "Efficacy and safety of the selective co-stimulation modulator abatacept following 2 years of treatment in patients with rheumatoid arthritis and an inadequate response to anti-tumour necrosis factor therapy," Annals of the Rheumatic Diseases, vol. 67, no. 4, pp. 547-554, 2008.

[16] S. Bombardieri, A. A. Ruiz, P. Fardellone et al., "Effectiveness of adalimumab for rheumatoid arthritis in patients with a history of TNF-antagonist therapy in clinical practice," Rheumatology, vol. 46, no. 7, pp. 1191-1199, 2007.

[17] S. Cohen, P. Emery, M. Greenwald et al., "Rituximab for rheumatoid arthritis refractory to anti-tumor necrosis factor therapy: results of a multicenter, randomized, double-blind, placebo-controlled, phase III trial evaluating primary efficacy and safety at twenty-four weeks," Arthritis and Rheumatism, vol. 54, no. 9, pp. 2793-2806, 2006.

[18] E. Keystone, R. Fleischmann, P. Emery et al., "Safety and efficacy of additional courses of rituximab in patients with active rheumatoid arthritis: an open-label extension analysis," Arthritis and Rheumatism, vol. 56, no. 12, pp. 3896-3908, 2007.

[19] S. Gabriel, M. Drummond, A. Maetzel et al., "OMERACT 6 Economics Working Group report: a proposal for a reference case for economic evaluation in rheumatoid arthritis," Journal of Rheumatology, vol. 30, no. 4, pp. 886-890, 2003.

[20] G. Kobelt, P. Lindgren, Y. Lindroth, L. Jacobson, and K. Eberhardt, "Modelling the effect of function and disease activity on costs and quality of life in rheumatoid arthritis," Rheumatology, vol. 44, no. 9, pp. 1169-1175, 2005.

[21] M. Osiri, P. Kamolratanakul, A. Maetzel, and P. Tugwell, "Cost effectiveness analysis of disease modifying antirheumatic drugs in rheumatoid arthritis," Rheumatology International, vol. 27, no. 11, pp. 1063-1069, 2007.

[22] G. Kobelt, "Thoughts on health economics in rheumatoid arthritis," Annals of the Rheumatic Diseases, vol. 66, supplement 3, pp. iii35-iii39, 2007.

[23] M. C. Weinstein, "Recent developments in decision-analytic modelling for economic evaluation," PharmacoEconomics, vol. 24, no. 11, pp. 1043-1053, 2006.

[24] A. Beresniak, A. S. Russell, B. Haraoui, L. Bessette, C. Bombardier, and G. Duru, "Advantages and limitations of utility assessment methods in rheumatoid arthritis," Journal of Rheumatology, vol. 34, no. 11, pp. 2193-2200, 2007.

[25] A. Kielhorn, D. Porter, A. Diamantopoulos, and G. Lewis, "Uk cost-utility analysis of rituximab in patients with rheumatoid arthritis that failed to respond adequately to a biologic diseasemodifying antirheumatic drug," Current Medical Research and Opinion, vol. 24, no. 9, pp. 2639-2650, 2008.

[26] M. Vera-Llonch, E. Massarotti, F. Wolfe et al., "Cost-effectiveness of abatacept in patients with moderately to severely active rheumatoid arthritis and inadequate response to tumor necrosis factor- $\alpha$ antagonists," Journal of Rheumatology, vol. 35, no. 9, pp. 1745-1753, 2008.

[27] A. J. Wailoo, N. Bansback, A. Brennan, K. Michaud, R. M. Nixon, and F. Wolfe, "Biologic drugs for rheumatoid arthritis in the medicare program: a cost-effectiveness analysis," Arthritis and Rheumatism, vol. 58, no. 4, pp. 939-946, 2008.

[28] G. Duru, J. P. Auray, A. Beresniak, M. Lamure, A. Paine, and N. Nicoloyannis, "Limitations of the methods used for calculating quality-adjusted life-year values," PharmacoEconomics, vol. 20, no. 7, pp. 463-473, 2002.

[29] M. McGregor and J. J. Caro, "QALYs: are they helpful to decision makers?" PharmacoEconomics, vol. 24, no. 10, pp. 947-952, 2006. 
[30] R. Ariza-Ariza, B. Hernández-Cruz, L. Carmona et al., "Assessing utility values in rheumatoid arthritis: a comparison between time trade-off and the EuroQol," Arthritis and Rheumatism, vol. 55, no. 5, pp. 751-756, 2006.

[31] C. A. Marra, J. C. Woolcott, J. A. Kopec et al., "A comparison of generic, indirect utility measures (the HUI2, HUI3, SF-6D, and the EQ-5D) and disease-specific instruments (the RAQoL and the HAQ) in rheumatoid arthritis," Social Science and Medicine, vol. 60, no. 7, pp. 1571-1582, 2005.

[32] B. Conner-Spady and M. E. Suarez-Almazor, "Variation in the estimation of quality-adjusted life-years by different preference-based instruments," Medical Care, vol. 41, no. 7, pp. 791-801, 2003.

[33] P. M. Welsing, H. L. Swinkels, L. A. Keimeney, and P. L. van Riel, "The relationship between disease activity, joint destruction and functional capacity over the course of rheumatoid arthritis," Arthritis and Rheumatism, vol. 44, no. 9, pp. 20092017, 2001. 


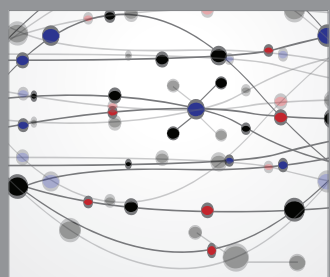

The Scientific World Journal
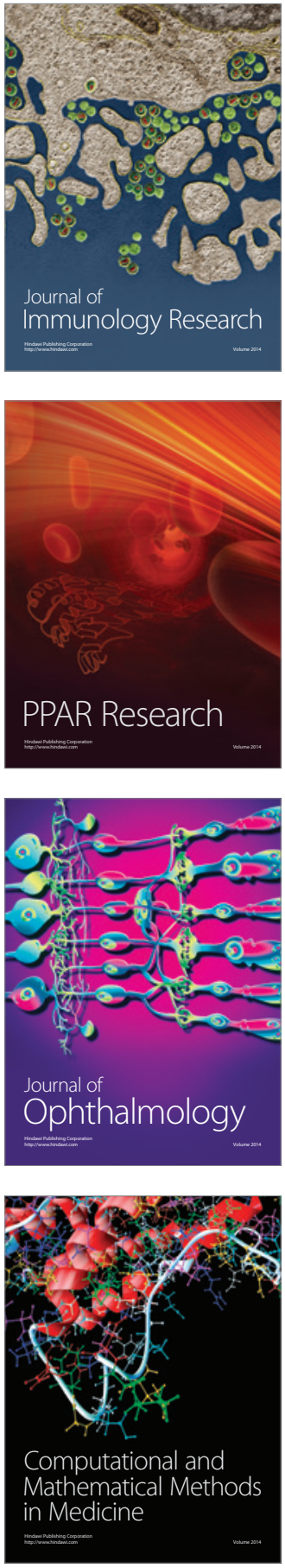

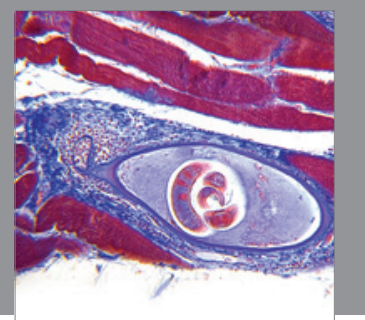

Gastroenterology

Research and Practice
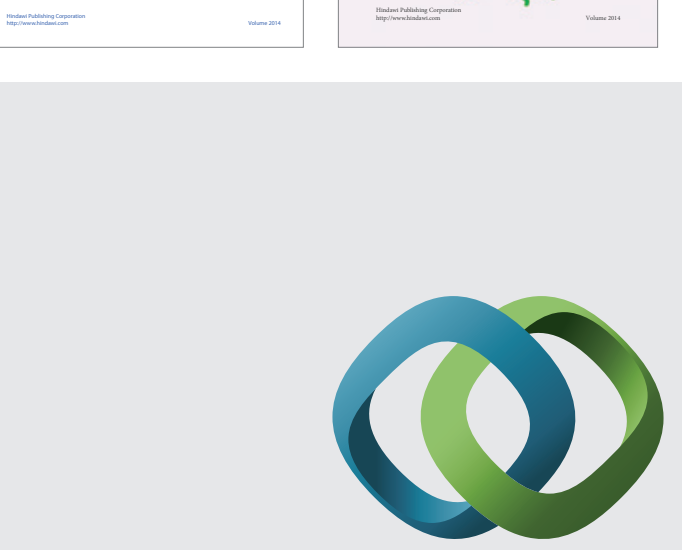

\section{Hindawi}

Submit your manuscripts at

http://www.hindawi.com
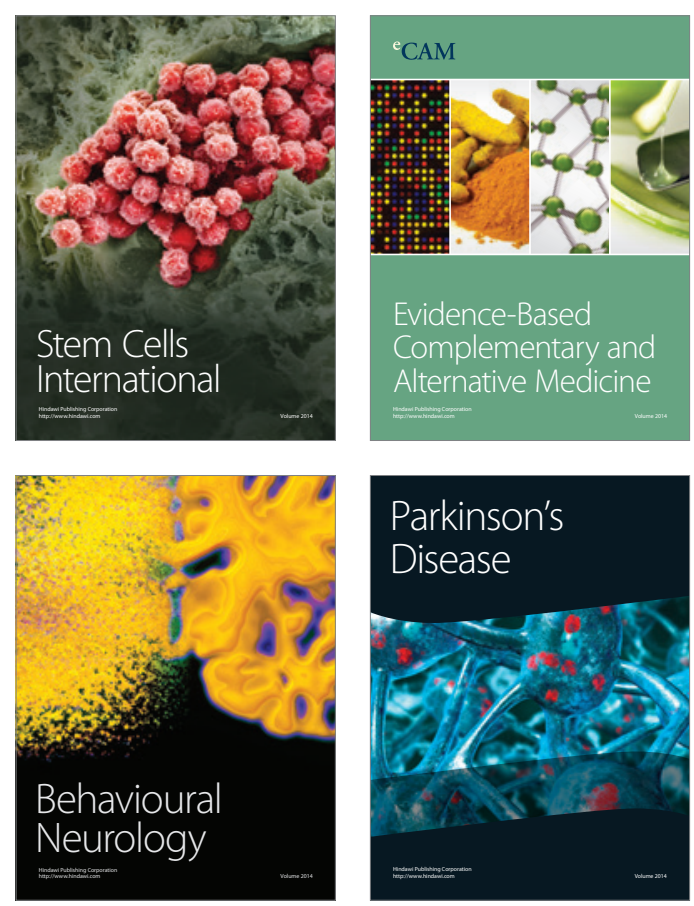

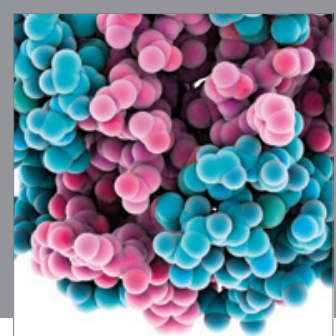

Journal of
Diabetes Research

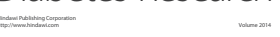

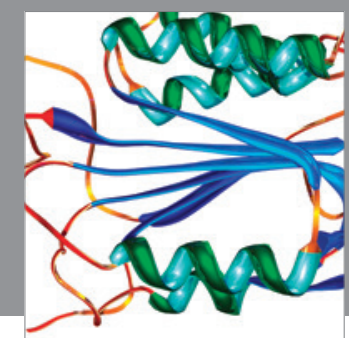

Disease Markers
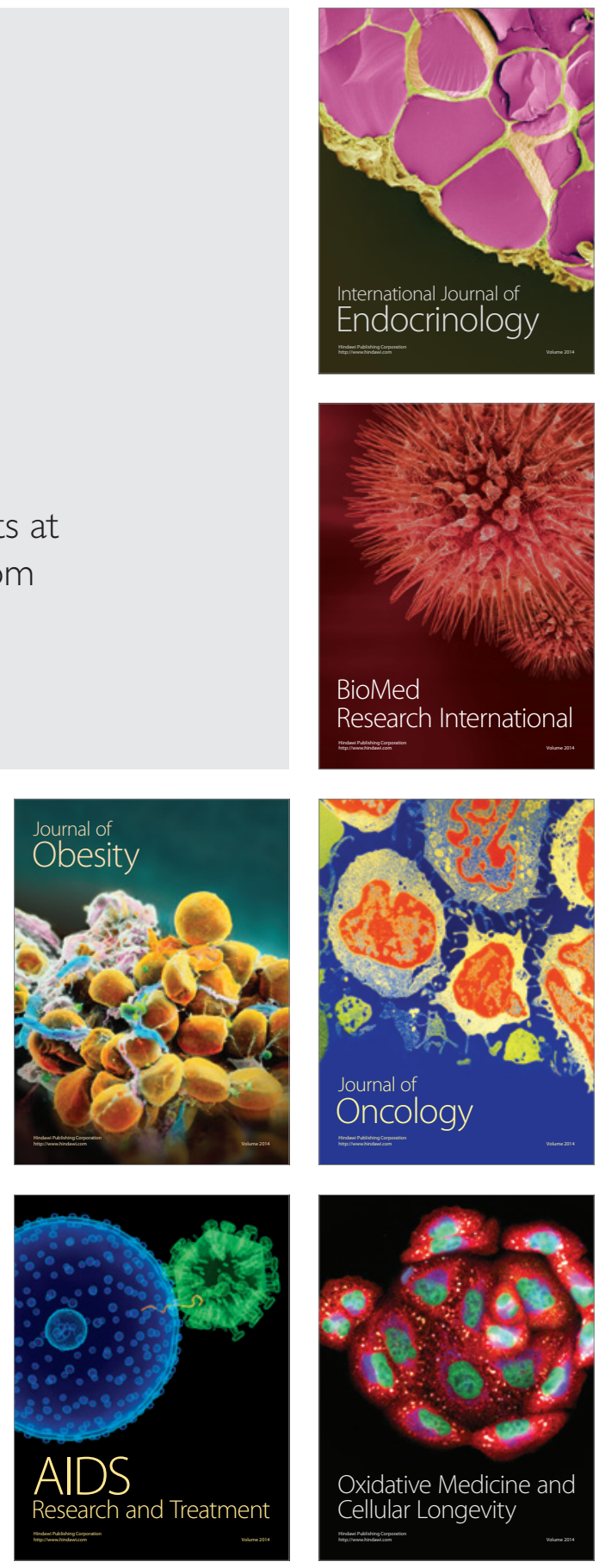